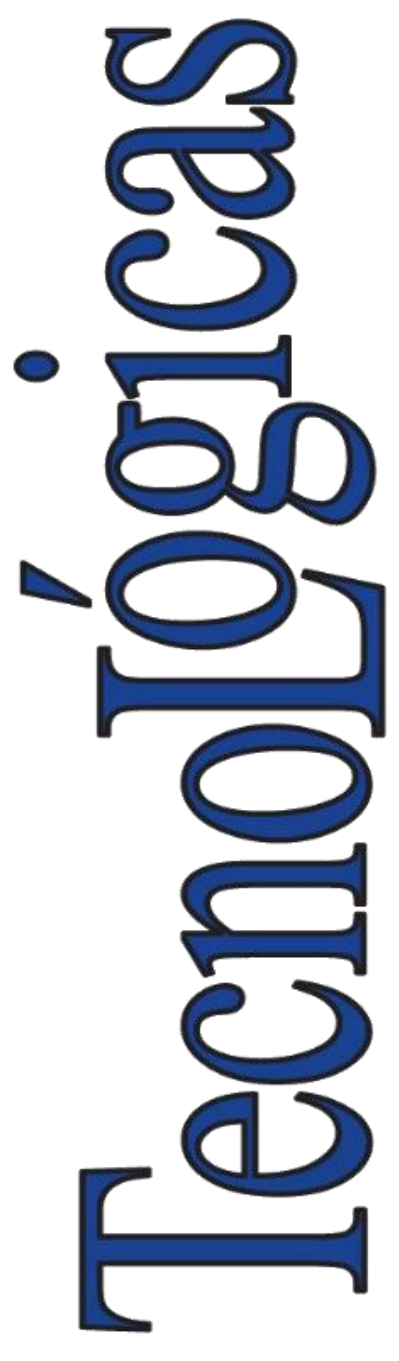

ISSN-p: 0123-7799 ISSN-e: $2256-5337$

Vol. 24, nro. 52, e1950, 2021

Recibido: 18 marzo 2021 Aceptado: 25 agosto 2021 Disponible: 21 septiembre 2021

CInstituto Tecnológico Metropolitano Este trabajo está licenciado bajo una Licencia Internacional Creative Commons Atribución (CC BY-NC-SA)

\section{Using X-Road to Implement Open Data in Electrical Systems and Promote the Integration with Smart City and Open Governance Strategies}

\section{Uso de X-Road para implementar datos abiertos en sistemas eléctricos y promover la integración con estrategias de ciudad inteligente $y$ gobierno abierto}

\author{
(D) Santiago Gil1; \\ (D) Germán D. Zapata-Madrigal2; \\ D Rodolfo García-Sierra ${ }^{3}$ \\ 1 Universidad Nacional de Colombia, Aarhus University, \\ Aarhus, Dinamarca, Medellín, Colombia, \\ sagilar@unal.edu.co; sgil@ece.au.dk \\ 2 Universidad Nacional de Colombia, Medellín, Colombia \\ gdzapata@unal.edu.co \\ ${ }^{3}$ Enel-Codensa, Energy Service Provider, Bogotá, Colombia, \\ rodolfo.garcia@enel.com
}

Cómo citar / How to cite

S. Gil; G. D. Zapata-Madrigal; R. García-Sierra, "Using X-Road to Implement Open Data in Electrical Systems and Promote the Integration with Smart City and Open Governance Strategies", TecnoLógicas, vol. 24, nro. 52, e1950, 2021. https://doi.org/10.22430/22565337.1950 


\begin{abstract}
The electrical industry is undergoing a deep digital transformation towards the consolidation of smart grids, which requires a high demand of data and information systems involved in the processes. Open data initiatives, which have been focused on open governance to a great extent, generate positive impacts on society and the economy in terms of easy access to public resources, agility, and transparency. These initiatives can also be adopted in the electrical industry (i.e., power, electrical, and energy systems) for customer engagement, collaboration with other industries, and reaching consensus. This study proposes the implementation of an open data solution for the electrical industry through the deployment of a data hub that offers digital services for smart city applications and the integration of the $\mathrm{X}$-Road system to improve the security and interoperability of open data. This initiative aims to promote a wider adoption of open data in the electrical industry and prepare the latter for fully connected and collaborative digital ecosystems in smart cities, industries, and governments. This study also proposes an open data architecture for the interoperability of the electrical industry with other digital industries (through a Smart City Hub and the adoption of 5G technology), and it reports some relevant results and major findings in this regard. This paper highlights the benefits of promoting open data and technological strategies for digitized electrical systems while considering humans an essential factor. Finally, it discusses the pros and cons of the integration of X-Road with the electrical industry under the concept of smart grids for data exchange and potential applications.
\end{abstract}

\title{
Keywords
}

Open Data, Integrated Services Digital Network, Smart City, Digitized Electrical Systems, City Hub.

\section{Resumen}

La industria eléctrica está experimentando una profunda transformación digital hacia la consolidación de redes inteligentes que necesitan una alta demanda de datos y sistemas de información involucrados en los procesos. Las iniciativas de datos abiertos, que en mayor medida han sido empleadas para iniciativas de gobierno abierto, generan impactos positivos en la sociedad y la economía en cuanto al fácil acceso a los recursos públicos, la agilidad y la transparencia. Estas iniciativas también se pueden adoptar en la industria eléctrica para sistemas de potencia, eléctricos y de energía para su uso en la participación de los clientes, la colaboración y la mejora de consenso en industrias. Esta investigación propone la implementación de una solución de datos abiertos para la industria eléctrica mediante el despliegue de un Hub que ofrece servicios digitales para aplicaciones de ciudad inteligente y la integración del sistema X-Road para mejorar la seguridad e interoperabilidad de los datos abiertos. Esta iniciativa pretende una adopción más amplia de datos abiertos en la industria eléctrica y su preparación para ecosistemas digitales totalmente conectados y colaborativos en ciudades inteligentes, industrias y gobierno. Se muestran algunos resultados relevantes y hallazgos importantes de este trabajo acerca de una arquitectura de datos abiertos para la interoperabilidad del sector eléctrico con otras industrias digitales a través de un Smart City Hub y la adopción tecnológica de 5G, exponiendo los beneficios de promover los datos abiertos y estrategias tecnológicas para sistemas eléctricos digitalizados mientras se considera el humano como factor esencial. Se discuten los pros y los contras de la integración de X-Road con la industria eléctrica dentro del concepto de redes inteligentes para el intercambio de datos y aplicaciones potenciales.

\section{Palabras clave}

Datos abiertos, red digital de servicios integrados, ciudad inteligente, sistemas eléctricos digitalizados, City Hub. 


\section{INTRODUCTION}

The concept of open data has been evolving due to the context of the Fourth Industrial Revolution, urbanization, digitization, and the use of information in production processes that involve the entire economy. This concept has generated significant impacts on smart cities, converging economy, government, people, mobility, the environment, and other aspects, which can be evaluated and monitored individually [1]. Open data initiatives can use data from public or private entities or a combination of both sectors, which is a field that shows potential to generate growth in society, strengthening the economy and improving people's access to knowledge. A success story in this regard was experienced in Estonia, where an open data strategy called X-Road was implemented since the beginning of this century. Such strategy involves the public and private sectors and people's access to information [2], [3].

This initiative has had an extremely positive impact in terms of the annual number of open data queries performed by its population. The model has even been distributed and replicated around the world as an open data channel between institutions and organizations.

Buenos Aires (Argentina) and Mexico City (Mexico) are two other regional success stories [4] that show the tools and rules that should be considered in government open data initiatives to enable, facilitate, and ensure the availability of the information to third parties.

The digitization of electrical systems and utilities and their integration with other areas (such as mobility, industry, communications, commerce, and people) have become more important in order to achieve value-added digital ecosystems and applications composed of physical and virtual assets [5]. Open data plays a relevant role in the deployment of digital ecosystems for power and energy systems in terms of improved quality science, effective collaboration, increased productivity, and societal debates. However, open data and open software are not used for other reasons, such as security concerns, know-how, and unwanted exposures [6]. Additionally, involving citizens in energy generation and consumption processes can improve their awareness, but being aware of energy losses in energy processes can be problematic nowadays, when we need to be more conscious consumers than ever before due to climate change [7].

In open data initiatives and information ecosystems, cybersecurity aspects are top priorities since their resources are exposed to threats of cyber-attacks [2], [8]. The resources and information in these types of systems are extremely critical because they can range from basic information on climate variables to government contracts or electoral data. Therefore, different strategies must be considered to guarantee the availability of the services in a safe way and the integrity of the information. The information should be immutable so that it cannot be corrupted by external attacks; for this purpose, blockchain technology can be used as an integrity validation tool [9]. Regarding smart grids and power systems applications, other strategies have been used to avoid denial of service, spoofing, interception, and intrusion, among other attacks [10].

Open data strategies should consider an additional aspect: the management of interoperability formats or protocols for data exchange. Therefore, their resources should implement adequate structures to share data between people and machines, including XML, XSD, JSON, and RDF. Furthermore, open data systems can implement semantic structures such as ontologies for the interoperable provision of data [11].

This study proposes the implementation of an open data system based on the X-Road exchange protocol of the Nordic Institute for Interoperability Solutions to be used in electrical systems and the integration with smart city applications, including smart metering data, energy market data, billing, and integrated services. The system is managed by a smart city hub that provides smart city services specially focused on energy and electricity data. The 
hub acts as a portal for open data and digital services, which can be a strategy to extend the portfolio of energy service providers. This approach aims to improve the interoperability, security, knowledge and data distribution, and interaction with third parties, such as people, industries, commerce, and the electrical grid.

The remainder of this paper is structured as follows: Section 1.1 reviews the state of the art, Section 2 presents the proposed architecture, Section 3 reports and analyzes the results, and, finally, Section 4 draws conclusions from the results and offers some future research directions.

\subsection{Related Works}

Several studies have proposed the implementation of open data initiatives in different fields, mainly open government data initiatives [12], but also open data for healthcare, utilities, energy, mobility, contracts, environment, housing, education, etc. According to Hossain et al. [12], open data initiatives cover the public, private, and mixed sectors of the economy, each one with different goals and perspectives, including technical, social, institutional/organizational, legal/ethical, economic, operational, political, general, or a combination of any of them. Some key factors for open data exploitation are political leadership, institutional pressure, and the emergence of digital technologies. This also applies to electrical and power systems, especially the rapid growth of digital technologies involved in their processes.

Open data initiatives aim to make a positive contribution to smart city contexts and their stakeholders by generating social and technical value. For instance, Pereira et al. [13] analyzed value generation for society when open government data was used in smart city applications. They found that these initiatives improve the services and information provided to citizens, government agencies, and other entities, as well as transparency, participation, collaboration, and the creation of new products and services. On the other hand, Viscusi et al. [14] proposed a classificatory framework to assess the social value generated by open government data initiatives, characterizing them by capability and wellbeing dimensions and indicators. They determined that it is important to have strategies to effectively guide the social and technical value toward stakeholders and use metrics such as the number of downloads, likes, visits, or star ratings. This is why classification frameworks are important for open data initiatives. Attard et al. [15] also reviewed several open government data initiatives, analyzing impacts on stakeholders, guidelines, and challenges and assessing frameworks for the life-cycle of open data.

In the field of power and energy systems, open data initiatives should be widely used for certain reasons, i.e., productivity, quality, and social impact. Nevertheless, the implementation of these initiatives is complex, which causes open data and research in this field to present a lag [6]. Emerging technologies such as the Internet of Things (IoT) in power and energy systems generate lots of data and information, which can be further exploited to generate positive impacts on the economy, quality of service, and society [16]. A similar concept, which has been used to promote green energy, is open data for electric and power systems as presented by Potosí-Guerrero et al. [17]. Open data initiatives should receive government incentives because they contribute to ensuring the quality of governance processes and to align digital ecosystems for the electrical industry. Energy matters, and publicly accessible, transparent, and understandable data about energy can be effectively shared with citizens in order to promote their participation [18]. Francisco and Taylor [19] designed a community-scale energy feedback system with augmented reality, as well as open energy consumption and supply data, which caused users to be very interested in having 
access to open urban energy data in any geographic location or community. This initiative also caused people involved to be interested in knowing more about efficient or inefficient equipment in buildings and to have better energy awareness. A good example of the applications of open data is energy consumption prediction with open smart metering data in buildings, as proposed by Miller [20]. The latter reviewed open prediction models for open data sets that help to understand different behaviors classified by building type. Anthony Jnr [21] reviewed various approaches of enterprise architectures and energy prosumption in smart cities to propose an architecture for energy prosumption management in residential buildings and electric vehicles in smart cities using open, online, and historical data. In addition, Terroso-Saenz et al. proposed the IoTEP platform [22], an open IoT-based system for energy data management and analysis. Said system focuses on data analysis and its application to buildings, but it also integrates additional software components to support external applications. Salazar-Zuluaga et al. [23] implemented a distributed communication network to manage distributed energy resources using the communication protocols of the IEC 61850 standard. This deployment achieved the integration of several logical nodes in photovoltaic generation plants, which enabled data acquisition under a common standard that can be used for technological solutions of renewable energy and the subsequent integration with wider power system architectures.

Regarding the information and communication technologies required to implement open data initiatives in electrical systems, Andreadou et al. [24] presented an extensive review of available telecommunication technologies and protocols that have been used in smart grid projects, with an emphasis on smart metering applications. Tightiz and Yang [25] also presented a comprehensive review of IoT protocols that can be implemented in smart grid applications, including AMQP, CORBA, CoAP, DDS, MQTT, OPC UA, XMPP, and ZeroMQ.

Similarly, Karpenko et al. [26] developed an interoperable IoT ecosystem that can be used for the integration of electrical systems in smart city applications. They investigated a case study of smart parking and charging for smart electric vehicles.

Another common way to provide open services and information to citizens is City Hubs or Data Hubs, which act as data/service portals that people can access. Heddebaut and Di Ciommo [27] proposed a City Hub that was used to improve services, fluidity, comfort, and energy efficiency in the transport infrastructure of smart cities. Lea and Blackstock [28] proposed the concept of City Hub, a portal to integrate data from different sources, including open data, transport, traffic, environment, utilities, etc. City Hubs use a platform as a service framework in order to offer services and data to stakeholders. Also, Bajer [29] proposed an IoT Hub integrated with cloud services to address the scalability and availability of the data.

Such hub integrates information from several sources, such as electricity and gas meters, meteorology stations, and a solar power plant. Furthermore, Gyrard et al. [30] implemented a semantic data hub that prioritizes interoperability and integration in machine-to-machine communication in applications of digital ecosystems.

Saputro et al. [31] compared X-Road e-government implementations in six adopter countries to establish the prerequisites to effectively deploy the X-Road data exchange protocol. They identified some requirements in legal framework support, political and leadership support, the integrity of the data, technical resources, personnel, and identity principles, among others. According to them, one of the most significant contributions of XRoad was the availability of e-services or web services for citizens in real-time, involving public and private sectors.

As reported in previous studies, open data initiatives can generate positive impacts on the economy and society. Strategies such as X-Road contribute to secure and structured ways to share open data and online web services to stakeholders in smart city contexts. Private and 
public sectors can significantly benefit from open data solutions, for instance, creating new digital services, improving collaboration between industries, and generating more customer engagement. The same applies to the electrical industry, which provides essential services for any process people carry out. Using open data, said industry can generate more engagement, consumer awareness, and strategies to optimize expenses and costs regarding electricity billing. However, there is still a gap that should be filled in order to achieve the consolidation of smart grids. The virtualization and digitization of assets, processes, and data are mandatory because they are fundamental concepts in smart grids. Interoperability and open data are also important and should be considered in fully integrated digital ecosystems for the electrical industry.

\section{MATERIALS AND METHODS}

This study proposes a 5G Data Hub, which is the result of a collaboration project between a university and an energy service provider in Colombia that united forces to promote digital and open data services in smart city applications supported by the existing electrical infrastructure, such as light and distribution poles. The aim of the 5G Data Hub for open data in electrical systems (which is based on the innovation Hub by Nokia and Telia) is to promote 5G technology in multiple activities of smart cities, offering experiences and services that require fast speed and reliable connections [32]. 5G technology is suitable for short-distance environments as it offers ultra-high speed, reliability, and low-latency that enable real-time connectivity [33]. Typical 5G architectures include femtocells or picocells that cover from meters to hundreds of meters [34], [35]. Streetlight and utility poles present a similar scenario because each one can cover a certain distance to provide connectivity and smart city services through the 5G Data Hub. The hub accesses public data from the government, open-source initiatives, and APIs and integrates data from internal projects and systems, analyzes the collected data, and, finally, presents the information to users or stakeholders as value-added visualizations and insights. The hub is intended to provide digital services and connectivity through cellular technologies as an opportunity to increase the interaction between people, the electrical industry, and other verticals of smart cities. In this study, the hub uses an NBIoT $4.5 \mathrm{G}$ modem, but it is expected to be integrated with $5 \mathrm{G}$ technology when it is completely available. Thus, this hub would provide IoT solutions and support virtual applications with high data transmission demands, such as virtual reality, augmented reality, and big data.

These components will characterize the 5G Data Hub as a tool to improve market value in digital ecosystems. The conceptualization of the 5G Data Hub is presented in Figure 1.

The open data architecture proposed in this study, which involves the integration of the 5G Data Hub, serves as a reference framework for implementing open data initiatives in smart city services based on energy and electrical systems data and infrastructure. In this architecture, cellular modems offer connectivity through $4.5 \mathrm{G}$ technology with a wide range of available communication protocols, such as UDP, TCP, PPP, HTTP, and MQTT. This guarantees that the hub stations have internet access, while improving energy consumption and providing enough speed to access open data. A future deployment will include 5G antennas instead of $5 \mathrm{G}$ modems or end-nodes. In this hub, the base architecture of X-Road [3] is the reference and central base of the system. This way, the smart city and utility services of the hub are available through the security, resource management, and authentication layers that X-Road provides. The architecture proposed here is presented in Figure 2. 


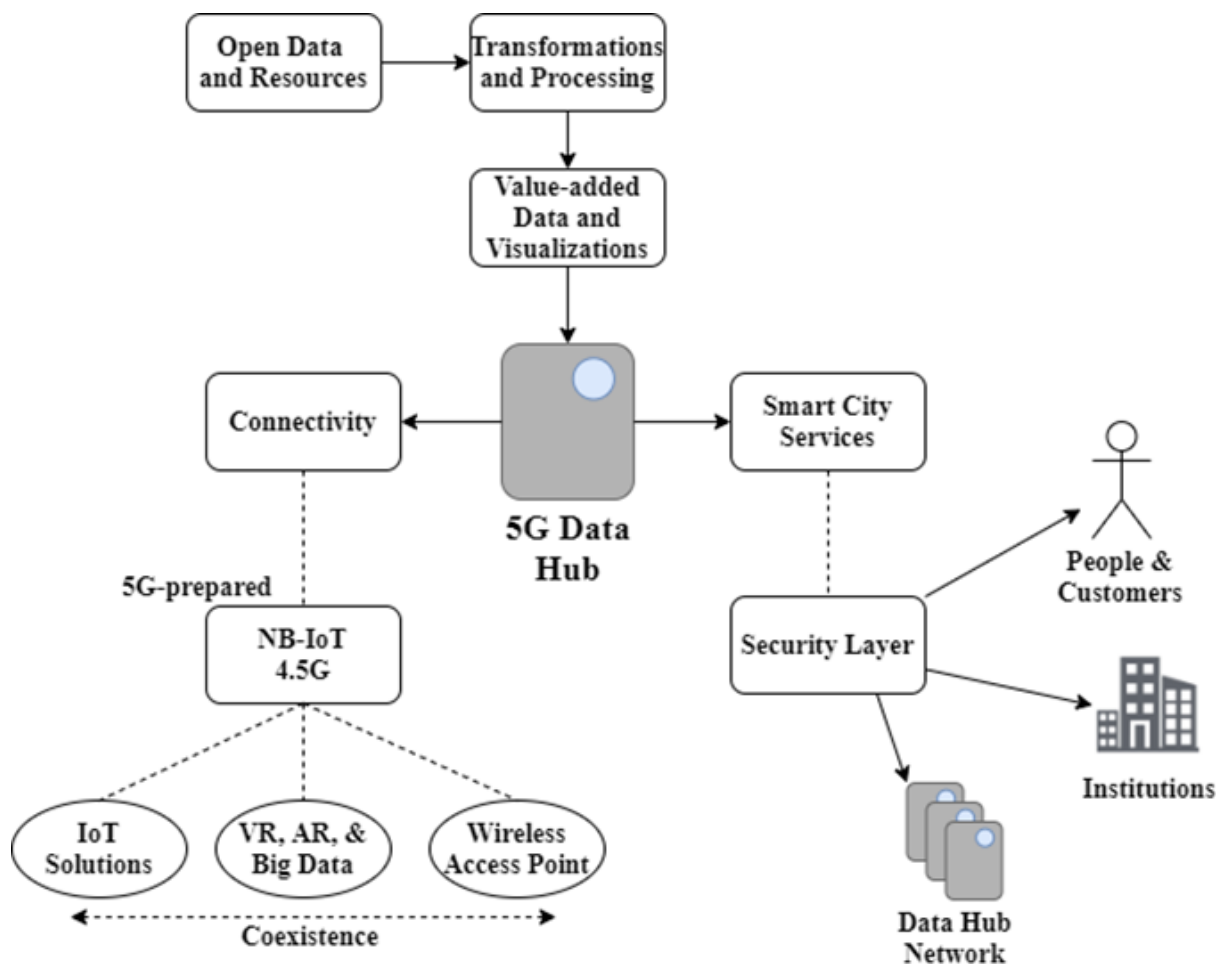

Figure 1. 5G Data Hub conceptualization. Source: Created by the authors.

The architecture includes a local deployment of X-Road, the hub, and the clients that consume the hub's services. According to the X-Road structure, every client must go through a proxy or secure interface on the X-Road security servers to reach service from any provider, thus becoming a type of security translator between clients and open information/data providers. X-Road supports the management of data exchange services based on the HTTP REST and SOAP protocols. All the hub's services are provided over the HTTP protocol, some of them are presented as REST services, and others as traditional HTTP, which, in short, represents no problem to be provided through the X-Road system. The difference between HTTP REST services and the handling of the traditional HTTP protocol, in terms of information exchange, is that, in REST, the messages are structured in JSON or XML formats, while, without using REST, messages can have any format, such as plain text, HTML, JSON, or any type of structure. Taking these considerations into account, REST services are provided to a greater extent to enhance interoperability and scalability in the system between the hub, X-Road, and stakeholders.

This implementation includes some important components within the system to guarantee data integrity and availability. For instance, it uses alternative protocols since X-Road only supports REST and SOAP, but other protocols such as MQTT can be used in the hub if necessary. Cybersecurity, authentication, and encryption of the information are provided by default X-Road features. Interoperability is provided through the use of interoperable protocols and machine-understandable data structures. Moreover, it offers automatic access to available open data in repositories and uses web scrapping. This approach also integrates some other strategies that can be implemented at a subsequent stage. Regarding cybersecurity, blockchain can be used to avoid the modification of the information; and, in terms of interoperability and data value, the Linked Data concept can be used to associate data structures with information models in the form of RDF triples. 
The next section describes the implementation and configuration of X-Road with the 5G Data Hub and different data sources that are used to exchange and visualize utility data.

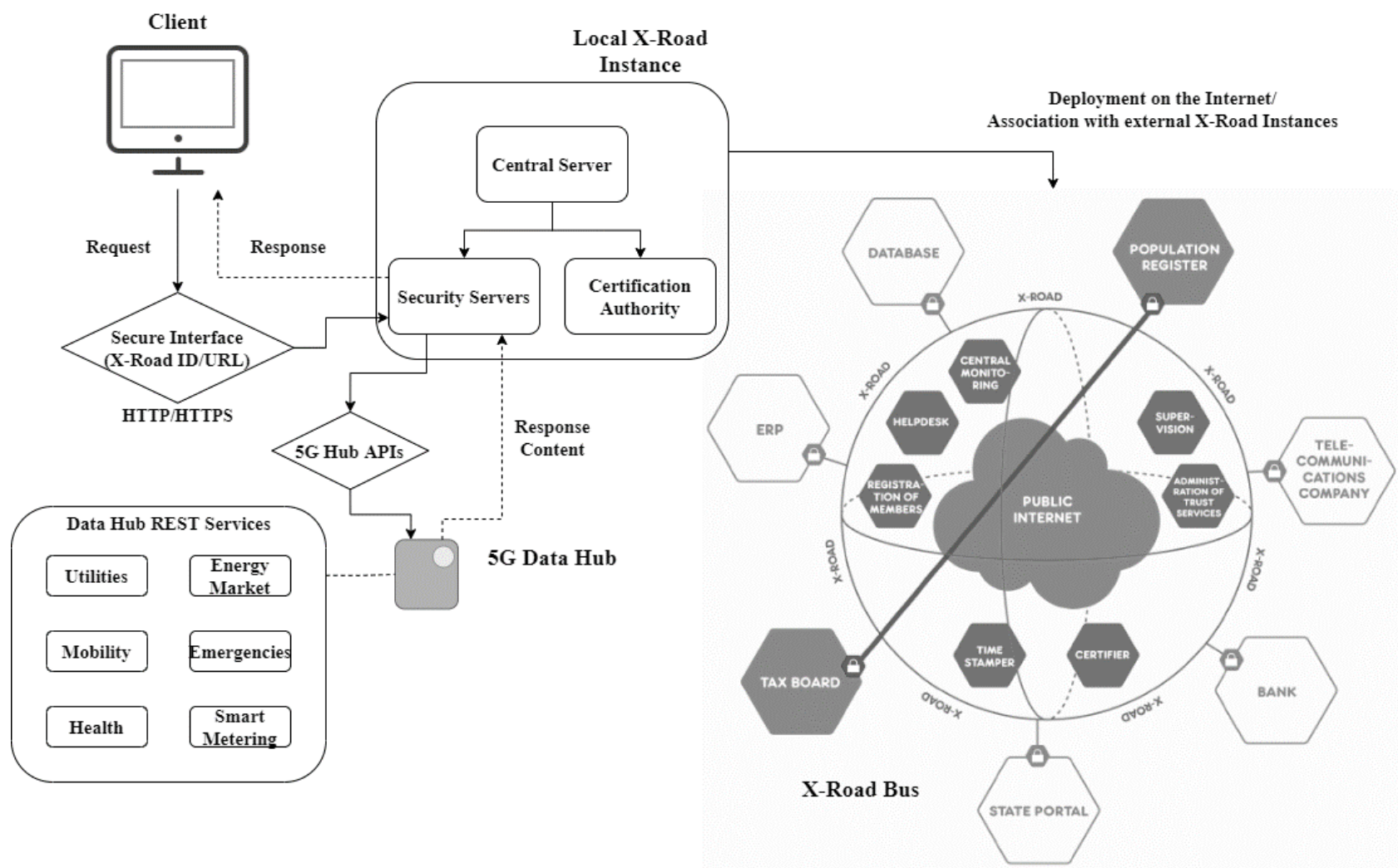

Figure 2. Open data architecture of the $5 \mathrm{G}$ Hub based on X-Road. Source: Created by the authors.

\section{RESULTS AND DISCUSSION}

This section describes the implementation of X-Road in a digital ecosystem designed to manage smart city services and electrical systems data. Such implementation takes advantage of the core architecture of X-Road [36] and integrations with an external information system to deal with open data about utilities, smart cities, and electrical systems, as described in Section 2. This section covers the deployment using a 4.5G-based hub (which acts as an information system provider/integrator), the X-Road integration and security layers, and the access to data on the client-side.

\subsection{System description and composition}

The system used here to carry out the open data integration is composed of several pieces of software and hardware. There are 3 main components: (1) the X-Road local server and its software components, (2) the 5G Hub module, and (3) the 5G Hub software application.

Finally, the client can be any HTTP-based client for requesting X-Road data and the mobile application for direct interaction with the $5 \mathrm{G} \mathrm{Hub}$, i.e., without the security layers of X-Road.

The implementation of X-Road includes a local deployment of an X-Road instance on an Ubuntu 20.04 machine. It includes the central server (CS), 2 security servers (SS1 and SS2), 
and the local certification authority (CA). The installation was performed according to the original structure provided in the GitHub repository [37]. Each server is provided with a specific IP address in the private network, and these IP addresses are used to access the service and validate requests via privileges and the certification authority.

In the central server, the security servers and certification services are configured, the users are created and granted privileges, and any subsystem created is approved to be used along with the local X-Road system. In this case, a user called "sgil" is created with member class "EDU" and member code " 1526 "; these data are then used to access the services. Figure 3 shows the central server in the member's view.

\begin{tabular}{|c|c|c|c|c|c|}
\hline $\mathbb{X}$ Central Server Administr $x$ & & X-Road $\otimes$ Security Server $x$ & X-Road $@$ Security Server $x$ Test CA & $x$ & + \\
\hline$\leftarrow \rightarrow$ C & (1) & A https://10.198.155.5:4000 & & & ..・它 \\
\hline $\begin{array}{l}\text { SG-UN } \\
\text { CENTRAL SERVER }\end{array}$ & & MEMBERS (2) & X X-ROAD & & \\
\hline CONFIGURATION & & & & & \\
\hline Members & & Search & & & \\
\hline Security Servers & & Member name & & Member class & Member code \\
\hline Global Groups & & codensa & & com & 1111 \\
\hline Central Services & & sgil & & EDU & 1526 \\
\hline $\begin{array}{l}\text { Certification Services } \\
\text { Timestamping Services }\end{array}$ & & & & & \\
\hline
\end{tabular}

Figure 3. X-Road instance - Central Server member view. Source: Created by the authors.

When the X-Road configuration is complete, the X-Road subsystems (i.e., services) are released on any of the security servers. Each subsystem has an owner and an ID to be accessed with the X-Road syntax. At this point, the 5G Hub services are mapped into X-Road subsystems. In the case of the utility services, there is a utility subsystem in X-Road that has several REST services which point to 5G Hub resources. Figure 4 shows the view of the utilities subsystem in X-Road with its specific REST services (for example, the water tariff or energy price API services) with the URL of the 5G Hub application. In other words, a service that is offered without security aspects at http://10.198.155.1:8000/utilities/energypriceAPI is translated into a different URL based on X-Road syntax; this time, it results in http://10.198.155.249/r1/SG-UN/EDU/1526/UTILITIES-HUB5G/utilities-

energypriceAPI. All the subsystems and members are configured in the local X-Road deployment, pointing the URLs of the Hub's services to X-Road URLs. X-Road settings are configured using the web interface. Additionally, the 5G Hub runs a Django server with specific URIs, and, internally, the server accesses open public data to be provided by the Hub.

Despite the fact that X-Road is oriented to information and open data exchange, the method it implements for authentication is quite strong and secure in order to improve transparency and reduce threats in information systems; that is why members and privileges need to be configured beforehand.

The 5G Hub includes a lightweight deployment on a Raspberry PI with an integrated NBIoT/LTE-M cellular module and a camera. The 5G Hub environment also features a Django application on the server-side and a mobile application with direct access to the Hub's services on the client-side. 


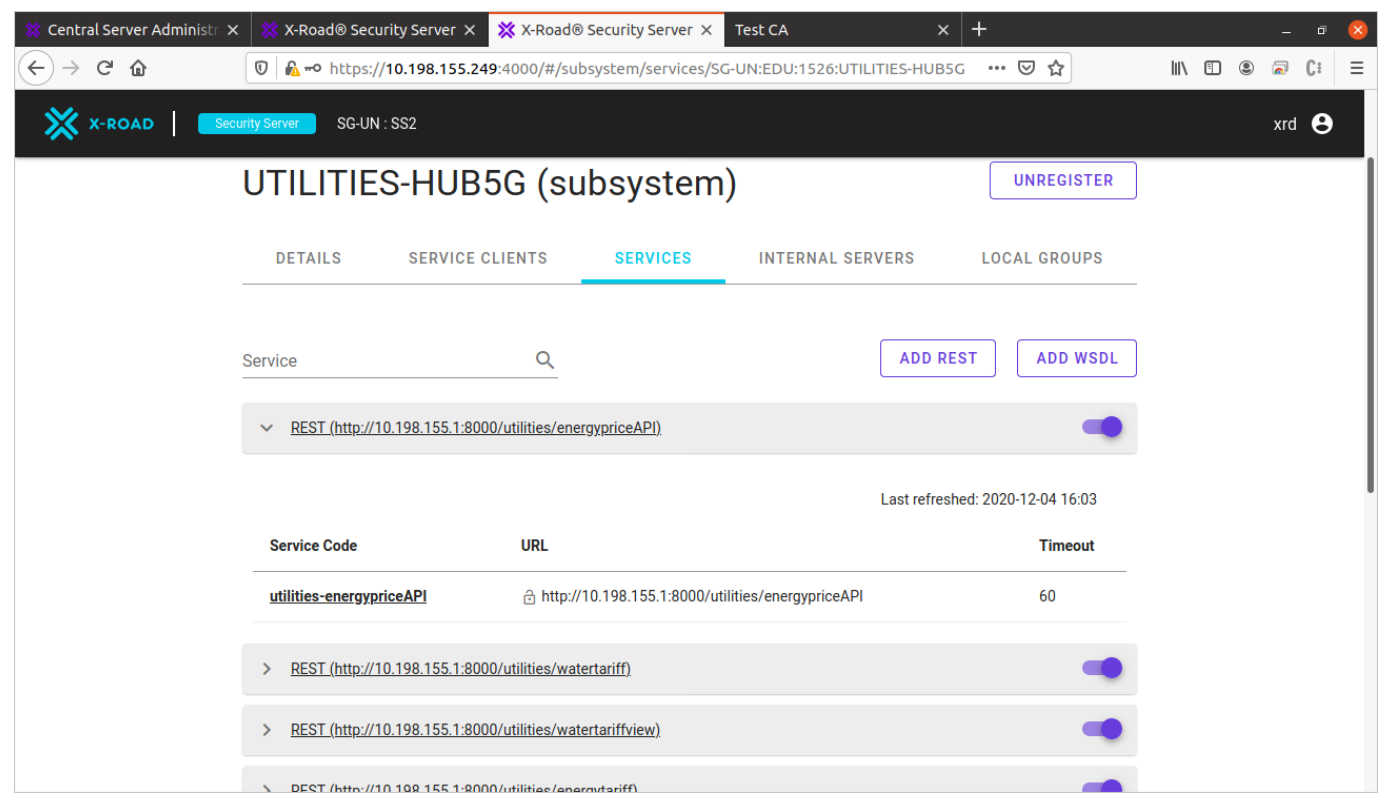

Figure 4. Utilities subsystem in X-Road. Source: Created by the authors.

The 5G Hub server-side application controls the cellular modem and the access to public and open data resources, processing the data and converting them into concise and easy-todeploy data and visualizations. The processed resources are then available on the Hub's server as URLs and APIs. Although the server application uses a model-view-controller framework, the views are data-oriented, i.e., no efforts are made to have amazing graphical interfaces on the client-side of the web application. Instead, these efforts are made in the 5G Hub mobile application. The mobile application, which is Android Studio-based, points to the Hub's resources directly, with no restrictions, because it is intended to be coupled to the Hub locally in the deployments as an interactive graphical user interface available for any citizen who wants to use it. The mobile application is composed of several views, each one designed for each available open data service. There are three view types (activities) in the mobile application: Google Maps Activities, WebView Activities, and basic activities for the control flow of the application. WebView Activities serve to parse the content of the $5 \mathrm{G} \mathrm{Hub}$ application (server-side) views, which enables an easy integration within the ecosystem During the data processing of both 5G Hub applications (i.e., server and mobile), structured formats are implemented to retrieve data from open sources, analyze the data, and transfer them from one application to the other. This enables the subsequent implementation with XRoad, which also suggests structured formats. Some of the structured formats used by X-Road are JSON, XML, CSV, and HTML. As proposed before, other semantic structured formats such as RDF can be subsequently embedded.

Finally, considering large-scale applications for open data initiatives with the Hub's services, X-Road becomes completely suitable to deliver the services to third parties because of its structure and features. Thus, the X-Road system serves as a secure and interoperable bridge between the Hub's services and stakeholders.

The main purpose of this integration between the 5G Data Hub and X-Road is promoting the use of open data in electrical, power, and energy systems (i.e., the electrical industry).

Hence, four applications show the suitability of this approach for said purpose: (1) the extraction of open data of the national energy market operator in Colombia directly from its webpage (https://www.xm.com.co/Paginas/Home.aspx) using web scrapping and making these data available on the 5G Data Hub and its further integrations; (2) the integration of 
the open energy price API of ComEd for real-time analysis of hourly energy pricing (https://hourlypricing.comed.com/api?type=5minutefeed); (3) the retrieval of historical open energy prices classified by tariffs, socioeconomic stratum, and cities of a local energy provider available at the open data portal of the Colombian government (https://datosabiertos.esri.co/); and (4) the retrieval of open smart electricity metering datasets to analyze consumption patterns and profiles of anonymous household users (https://smda.github.io/smart-meter-data-portal/). The 5G Hub also offers other smart city services that are not related to the electrical industry or power systems, such as mobility, utilities (water and gas), security, weather, healthcare (regarding the coronavirus), and emergencies. Said hub represents the opportunity of a convergent solution for the electrical industry, but it also considers other verticals of Industry 4.0 and smart cities.

\subsection{Deployment}

The deployment of the scenario is available once all the modules are up and assembled. The core depends on the 5G Hub server application, which retrieves the data from open sources. The open data portals used in this deployment are MEData (http://medata.gov.co/); ESRI Colombia (http://datosabiertos.esri.co/); the open data portal of the Área Metropolitana del Valle de Aburrá (https://datosabiertos.metropol.gov.co/); the open data portal of Colombia (https://www.datos.gov.co/); SIATA portal (https://siata.gov.co/siata_nuevo/); ComEd's hourly pricing API (https://hourlypricing.comed.com/api?type=5minutefeed); XM, i.e., the Colombian energy market operator (https:/ /www.xm.com.co/Paginas /Home.aspx); and the smart meter data portal (https://smda.github.io/smart-meter-data-portal).

All the open data repositories in this application serve a relevant purpose for this study. For that reason, they differ in domain and context but do provide specific content related to electrical systems and the institutions involved in their execution. However, other reliable open data sources can be integrated seamlessly if the scope is different. Some alternative open data sources for energy systems that can be used reliably are, for example, the EnergiNet repository of the Danish government (https://en.energinet.dk/Electricity/Energy-data); Open Power System Data, a contribution between companies and universities (https://open-powersystem-data.org/); the open data of the US Energy Information Administration (https://www.eia.gov/electricity/data.php); open energy data on the European Data Portal (https://data.europa.eu/it/highlights/open-energy-data-european-data-portal); and OECD Energy data (https://data.oecd.org/energy.htm). Readers are encouraged to replicate this solution and integrate any other open datasets as required.

The server processes and transforms the data into value-added data, charts, or APIs. Access to internet-based resources is provided by the cellular modem. The latter is coupled to the 5G Hub via USB and provides connectivity using the WVDIAL system, which provides direct internet access through dial-up. It is possible to provide connectivity using alternative methods with the protocols available in the modem, such as HTTP, MQTT, or TCP sockets.

The WVDIAL method was selected because of its simplicity and the robustness of the connection. Finally, the data is provided through the client interfaces. The 5G Hub mobile application offers a graphical user interface, but it is intended for local interaction, as an interactive tool of smart cities. On the other hand, X-Road is intended to provide secure and standardized open data and data exchange. The X-Road client differs from the mobile application client because the data is presented in a different way, i.e., the former is completely data-driven, and the latter is interactive. Figure 5 provides a broad overview of the system interaction considering all the components previously described. 


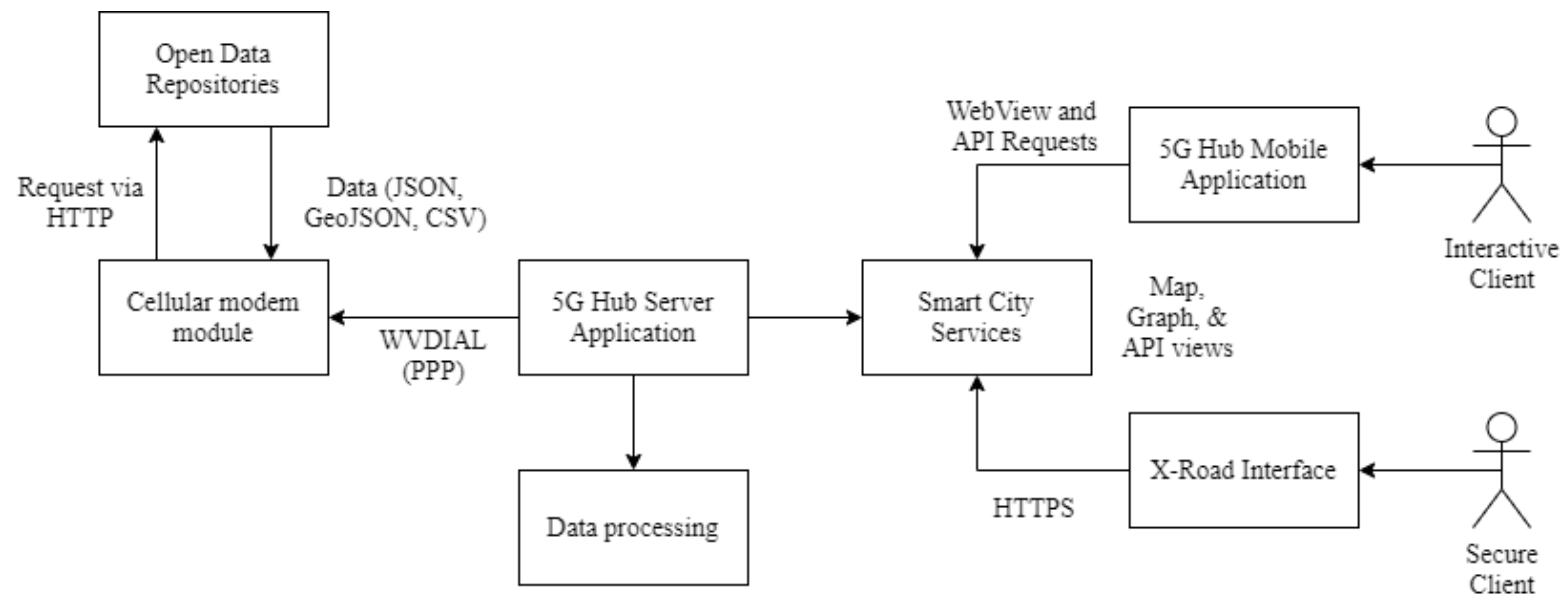

Figure 5. Interaction diagram of the system integration. Source: Created by the authors.

The original URIs to access the Hub's services are common web service URIs, but, due to the integration of X-Road, the services should be accessed via the X-Road URI notation, whether they use HTML for visualizations or JSON for data. Table 1 presents only the available smart services related to the electrical industry. The other services related to different verticals also have their specific X-Road paths to be accessed, but they are not mentioned in this paper.

Table 1. Service descriptions and accessibility with X-Road. Source: Created by the authors.

\begin{tabular}{|c|c|c|c|}
\hline Service description & Service URI (Original) & Service URI (X-Road) & Service type \\
\hline $\begin{array}{l}\text { This resource points to } \\
\text { the ComEd energy } \\
\text { price API for real-time } \\
\text { analysis of hourly } \\
\text { pricing. }\end{array}$ & /utilities/energypriceAPI & $\begin{array}{l}\text { /r1/SG- } \\
\text { UN/EDU/1526/UTILITIES- } \\
\text { HUB5G/utilities- } \\
\text { energypriceAPI }\end{array}$ & JSON (REST) \\
\hline $\begin{array}{l}\text { This resource points to } \\
\text { the energy tariff data } \\
\text { of the local energy } \\
\text { service provider. }\end{array}$ & /utilities/energytariff & $\begin{array}{l}\text { /r1/SG- } \\
\text { UN/EDU/1526/UTILITIES- } \\
\text { HUB5G/utilities-energytariff }\end{array}$ & JSON (REST) \\
\hline $\begin{array}{l}\text { This resource points to } \\
\text { the energy tariff data } \\
\text { of the local energy } \\
\text { service provider } \\
\text { displayed graphically. }\end{array}$ & /utilities/energytariffview & $\begin{array}{l}\text { /r1/SG- } \\
\text { UN/EDU/1526/UTILITIES- } \\
\text { HUB5G/utilities-energytariff- } \\
\text { view }\end{array}$ & View (HTML) \\
\hline $\begin{array}{l}\text { This resource points to } \\
\text { the data of the market } \\
\text { extracted from the } \\
\text { national energy } \\
\text { market operator using } \\
\text { web scrapping. }\end{array}$ & /utilities/marketdata & $\begin{array}{l}\text { /r1/SG- } \\
\text { UN/EDU/1526/UTILITIES- } \\
\text { HUB5G/utilities-marketdata }\end{array}$ & JSON (REST) \\
\hline $\begin{array}{l}\text { This resource extracts } \\
\text { open smart electricity } \\
\text { metering data and } \\
\text { retrieves different } \\
\text { value-added charts. }\end{array}$ & /utilities/smartmetering & $\begin{array}{l}\text { /r1/SG- } \\
\text { UN/EDU/1526/UTILITIES- } \\
\text { HUB5G/utilities- } \\
\text { smartmetering }\end{array}$ & View (HTML) \\
\hline
\end{tabular}


Due to the nature of the operation of X-Road, what is obtained through the services offered on the platform is typed data, which can be structured or raw data. In the case of REST Web services, a structured response in JSON or XML format is expected; and, in the case of SOAP Web services, a structured response in XML format is expected. The benefit of using REST is that the services use HTTP as the application protocol, so it is possible to send the data in HTML format; then, whole files or text through the service are allowed, although that is not its purpose. This represents a great advantage since some of the services available in the Hub are presented directly in the graphical interface via HTML. For example, the smart electricity metering service, which depends on hundreds of thousands of entries, just shows analysis graphs instead of sending them as structured data, which is also possible. Figure 6 shows the results of integrating the Data Hub and X-Road with some data available on the webpage of XM (i.e., the Colombian energy market operator). The processed open data are available on the mobile application and on X-Road, both in Spanish as this is the official language in Colombia.

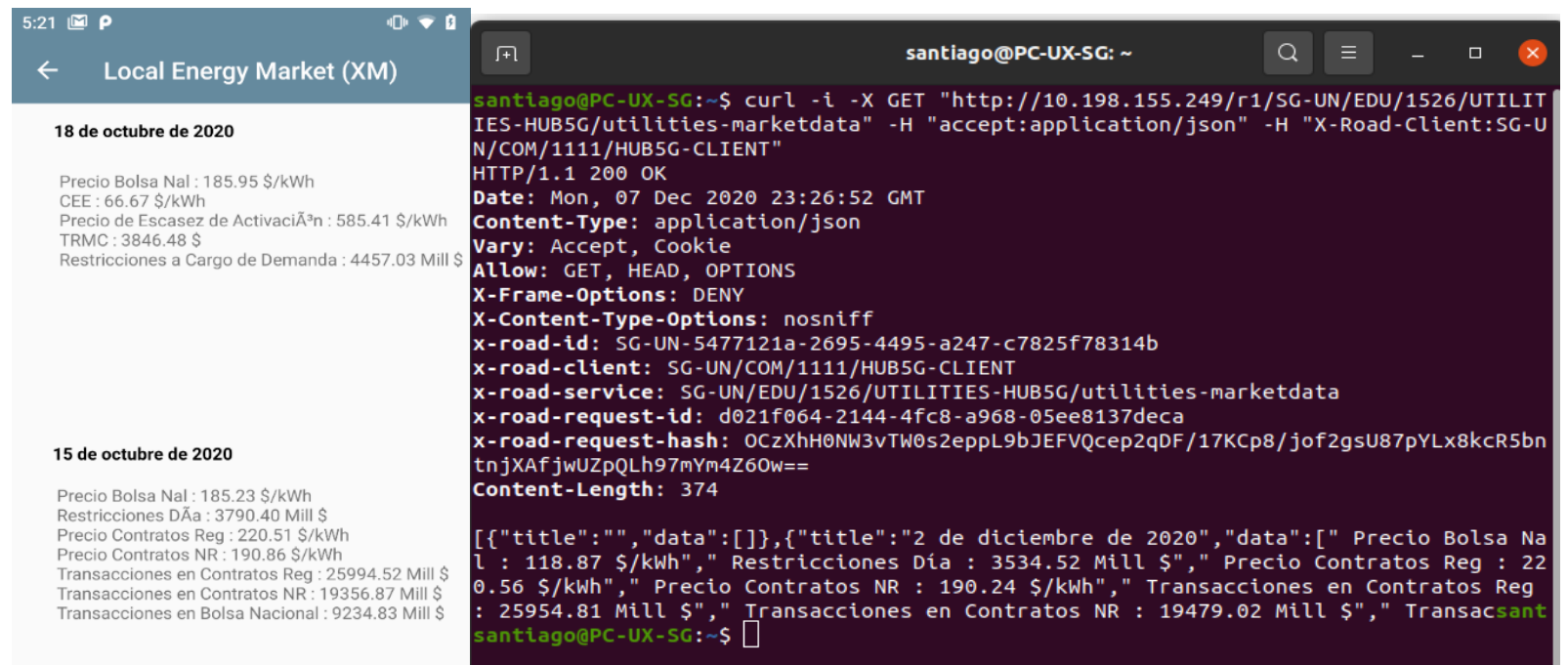

Figure 6. Open data resource for the energy market. Left: the resource accessed via the Mobile Application. Right: the service accessed via X-Road. Source: Created by the authors.

The same occurs in Figure 7, which shows the integration of the open smart electricity metering data with the Data Hub and X-Road. Due to the HTML view of this service, which retrieves a lot of entries and performs a data analysis on the dataset, the service from X-Road is at a first step, requested and saved to a file; then, the HTML file can be opened on any browser. Even if it is a static HTML, it preserves the dynamic charts thanks to JavaScript, which is great for this approach. This method is easily implementable using cURL and saving it with a Linux console.

In the case of the energy market service, the commands are the following: curl $-i-X G E T$ "http://10.198.155.249/r1/SG-UN/EDU/1526/UTILITIES-HUB5G/utilities-marketdata" -H "accept:application/json" -H "X-Road-Client:SG-UN/COM/1111/HUB5G-CLIENT". The GET method refers to the X-Road service URL and the request requires 2 headers, i.e., the accepted format and the member accessing the resource. This time, the member belongs to "codensa," as seen in Figure 3. 


\section{$5: 46 \bullet \sqcap P P$ \\ $\leftarrow \quad$ Smart Metering (Open Data)}
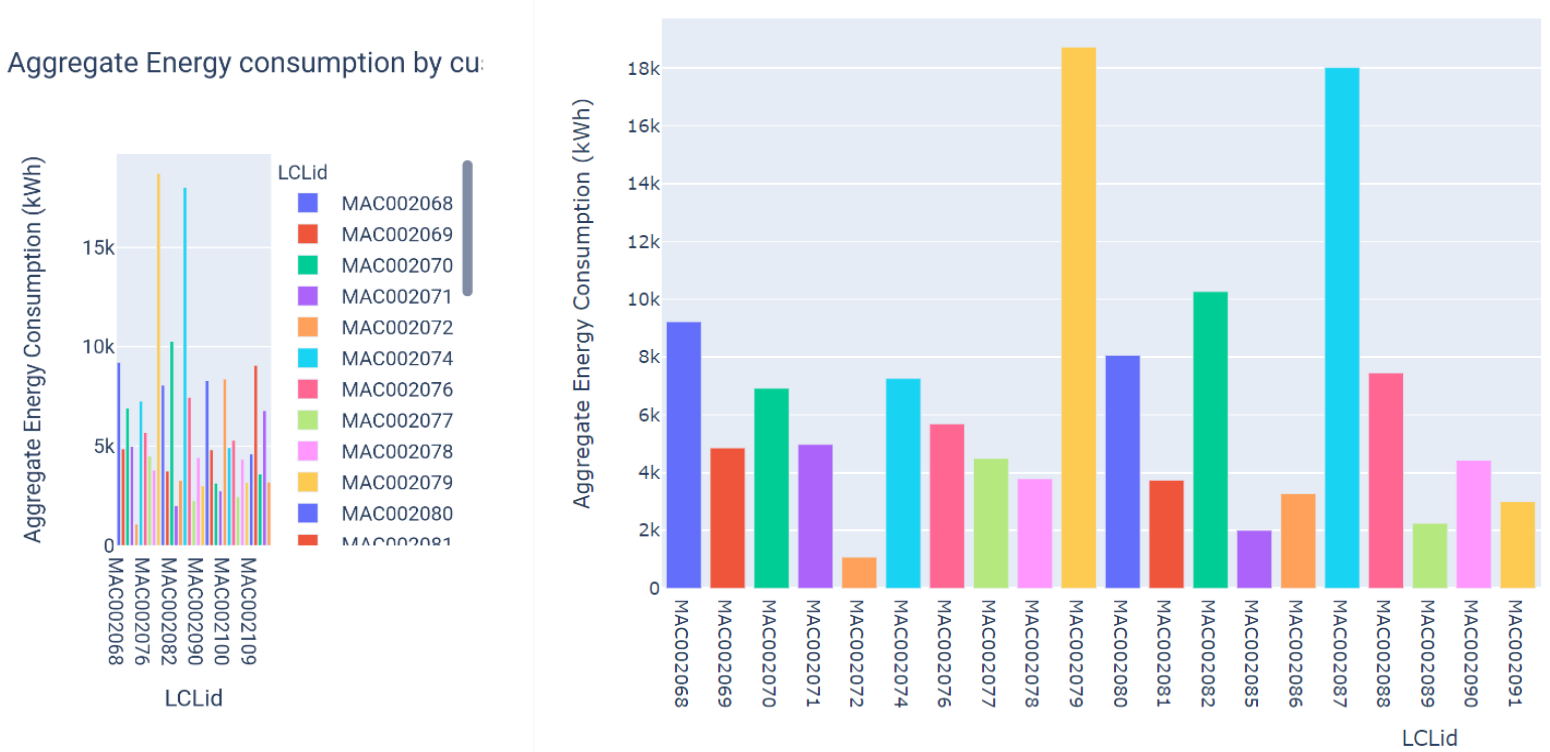

Figure 7. Open data resource for smart electricity metering. Left: the resource accessed via the Mobile Application. Right: the service saved from X-Road as an HTML file and displayed on a browser

Source: Created by the authors.

In the case of the smart metering service, the method is the following: curl $-i-X G E T$ "http://10.198.155.249/r1/SG-UN/EDU/1526/UTILITIES-HUB5G/utilities-

smartmetering" $\quad-H \quad$ "accept:application/json" $\quad-H \quad$ "X-Road-Client:SGUN/COM/1111/HUB5G-CLIENT" > smart_metering_hubg_xroad.html. The GET method refers to the X-Road service URL again and the headers for accepted format and member, which, this time, belongs to "sgil," as seen in Figure 3. The section after the ">" symbol indicates that the response is being saved to a file. HTML files preserve headers retrieved from X-Road, but they can be omitted. The other services follow the same pattern for JSON (without saving to a file) and HTML views (saving to a file). The method to obtain the data from X-Road uses HTTP or HTTPS (with or without a certificate) for the X-Road endpoint, which retrieves the information that the 5G Data Hub offers, but with an additional security layer for the open data. The use of X-Road has several positive impacts on the exchange of data, not only open data, but also any raw data, document, or structured data that can be encapsulated in HTTP messages. X-Road offers a secure and interoperable layer suitable for communication in large-size networks, and it can be used to manage privileges, rules, and structure to connect institutions, machines, and people in different channels, which makes it an excellent tool for electrical systems.

\section{DISCUSSION}

Regarding the pros and cons of this approach, its benefits are more noticeable than its disadvantages to a great extent. Its interoperability and security for data exchange in open data or private environments are the most important impacts to highlight. This is because 
the functional properties of power systems (such as power supply, communication between equipment, or the ability to recover) are usually considered top priorities in cybersecurity approaches [38]. This approach offers another perspective of cybersecurity for open data in electric power systems. The secure integration with external information systems is relevant in this approach too because it enables the inclusion of electrical systems' data, regardless of their origin, to be used in the digital ecosystems of smart grids. A good example of this is the application of the $5 \mathrm{G} \mathrm{Hub}$ to integrate smart city services, using the electrical infrastructure as a basis and covering a wide range of verticals that are integrated into electrical systems and involved processes. All the protocols that are used in the system are standardized and commonly implemented in all industries, which is a great advantage for interoperability and integrity. If any specific protocol is further required, it can be easily integrated with the already available protocols of this approach. According to Bolaños et al. [39], strategies that cover a broader population in terms of age and habits (e.g., virtual assistants and easy-to-use interfaces) can be implemented to enhance the adoption of these kinds of technological solutions.

On the other hand, using this approach causes some complications. First, it requires a dedicated server to run the X-Road system, which needs specific components and $l x d$ containers to run. So far, it is only compatible with Linux, which can be a limitation for some institutions. The 5G Hub application can be replaced with any other suitable option for specific purposes (e.g., a billing system, a smart metering service, a coordinator for open Distributed Energy Resources, or a combination of all), but it requires a custom deployment of the application and the integration with the X-Road system. In other words, it requires work hours and trained people, which translates into money, time, and resources. Finally, open data initiatives are barely starting; thus, incorporating open data, files, and services could need additional permissions or privileges according to the criticality of data. This task could be challenging and require further methods to guarantee the integrity of data (e.g., blockchain). Therefore, complications can arise during the deployment of open data initiatives in an industry that is composed of critical infrastructure.

\section{CONCLUSIONS}

In summary, this study proposes the implementation of open data initiatives in electrical, power, and energy systems of the electrical industry through the integration of a smart city hub that offers digital services. This application takes advantage of existing electrical infrastructure, available open data and resources, and IoT to provide a solution that promises to be convergent regarding the collaboration of the electrical industry, people, other industries, and commerce.

This approach also offers some relevant advantages in terms of open data for applications in electrical systems. It defines a way to extract, process, and share data in open data initiatives. Electrical systems are characterized by numerous complex variables that generate a lot of data, which can be analyzed or reused to enhance accuracy and performance regardless of the scale of the system. Undoubtedly, there are a lot of data to be shared between markets of different industries in order to generate value-added solutions and insights for energy consumers and providers. Not just data themselves, but also metadata can be openly available to reach a consensus regarding the solutions, standards, and roadmaps of this industry.

Importantly, electrical systems are undergoing a deep digital transformation towards smart grids. As a result, considering the implementation of new technological and digital services is extremely important as a factor to consolidate interoperable ecosystems in the 
electrical industry and its interaction with other industries. At this point, open data services are essential for the collaboration of different verticals in completely implemented virtual ecosystems for smart cities, smart industries, and digital government.

Open data initiatives should be strategically and securely oriented and managed. Open data should guarantee the integrity and security of clients and providers, especially in critical infrastructures such as the electrical one. Therefore, cybersecurity methods and membership can be implemented according to sensitivity, criticality, and relevance. Also, open resources must be able to be secured with specific features according to the requirements. Fortunately, tools like X-Road contribute to these objectives by providing security layers, interoperability, and membership. Such tool enables communication for institutions, machines, and people with a convergent technology for data exchange. X-Road-based applications support largescale deployments, which enables large-size networks to integrate smart city ecosystems, massive data, and even crowdfunding data.

However, some aspects should be improved or considered. One of them is the big data capability, which is not available nor supported in the system at this moment; nevertheless, it should be covered in the context of open big data. 5G technology could contribute to meet this requirement and support related services, such as virtual and augmented reality provided via the Hub. A great option to be integrated into this solution, as mentioned before, is blockchain as an integrity validator of open data resources. Open source blockchain platforms like Ethereum can be used to validate the integrity of the data, information, or files transmitted from providers to clients. Similar to the XML or JSON files/formats used in the system proposed here, RDF documents should be implemented with model-based open data that can be obtained from the instantiation of ontological models. This feature would enable the distribution of open data and open knowledge of data and information systems of any vertical. Future research can also conduct a comprehensive review, with bibliometric analyses, of the uses of open data in electrical systems and other industries.

This study made three key contributions: (1) integrating X-Road and IoT data for electrical systems and smart city applications; (2) implementing secure communication for open data of electrical systems from different data sources and formats; and (3) showing the impact that 5G or similar technologies can have on digital ecosystems and environments in smart cities, covering different industries and verticals. Nevertheless, three known limitations were also identified: (1) the reliability and trustworthiness of open data should be validated; (2) data exchange services that are too large (lots of bytes of information) can generate compatibility problems with X-Road; and (3) membership management and association with other central servers are critical since they should be managed by a transparent institution that has the availability and infrastructure to deploy an X-Road network instance with load balancing.

\section{ACKNOWLEDGMENTS}

This study received no external funding.

\section{CONFLICTS OF INTEREST}

The authors declare that there is no conflict of interest. 


\section{AUTHOR CONTRIBUTIONS}

S.Gil, implemented the system, analyzed and validated the results, and drafted the manuscript.

G. D. Zapata-Madrigal. supervised and managed the project and revised and edited the final manuscript.

R. García- Sierra conceptualized the study and managed and supervised the project.

\section{REFERENCES}

[1] F. T. Neves; M. de Castro Neto; M. Aparicio, "The impacts of open data initiatives on smart cities: A framework for evaluation and monitoring," Cities, vol. 106, p. 102860, 2020. https://doi.org/10.1016/j.cities.2020.102860

[2] Fundación Real Instituto Elcano, "Las embajadas de datos: la protección de la información estatal," 2014. $\underline{\mathrm{URL}}$

[3] OECD iLibrary, "Case Study: The Estonian Education Information System (EHIS)," Strength. Gov. Ski. Syst. Lessons from Six OECD Ctries, pp. 39-60, Apr. 2020. https://doi.org/10.1787/298d6678-en

[4] C. Bonina; B. Eaton, "Cultivating open government data platform ecosystems through governance: Lessons from Buenos Aires, Mexico City and Montevideo,” Gov. Inf. Q., vol. 37, no. 3, p. 101479, Jul. 2020. https://doi.org/10.1016/j.giq.2020.101479

[5] Y. Lu, "Industry 4.0: A survey on technologies, applications and open research issues," J. Ind. Inf. Integr., vol. 6, pp. 1-10, Jun. 2017. https://doi.org/10.1016/j.jii.2017.04.005

[6] S. Pfenninger; J. De Carolis; L. Hirth; S. Quoilin; I. Staffell, "The importance of open data and software: Is energy research lagging behind?" Energy Policy, vol. 101, pp. 211-215, Feb. 2017. https://doi.org/10.1016/j.enpol.2016.11.046

[7] A. Ambrose, "Walking with Energy: Challenging energy invisibility and connecting citizens with energy futures through participatory research," Futures, vol. 117, p. 102528, Mar. 2020. https://doi.org/10.1016/j.futures.2020.102528

[8] D. B. Rawat; R. Doku; M. Garuba, "Cybersecurity in Big Data Era: From Securing Big Data to Data-Driven Security," IEEE Trans. Serv. Comput., pp. 1-1, Mar. 2019. doi: https://doi.org/10.1109/tsc.2019.2907247

[9] C. Xu et al., "Making Big Data Open in Edges: A Resource-Efficient Blockchain-Based Approach," IEEE Trans. Parallel Distrib. Syst., vol. 30, no. 4, pp. 870-882, Apr. 2019. https://doi.org/10.1109/TPDS.2018.2871449

[10] M. A. Ferrag; M. Babaghayou; M. A. Yazici, "Cyber security for fog-based smart grid SCADA systems: Solutions and challenges," J. Inf. Secur. Appl., vol. 52, p. 102500, Jun. 2020. https://doi.org/10.1016/j.jisa.2020.102500

[11] S. Aydin; M. N. Aydin, "Ontology-based data acquisition model development for agricultural open data platforms and implementation of OWL2MVC tool," Comput. Electron. Agric., vol. 175, p. 105589, Aug. 2020. https://doi.org/10.1016/j.compag.2020.105589

[12] M. A. Hossain; Y. K. Dwivedi; N. P. Rana, "State-of-the-art in open data research: Insights from existing literature and a research agenda," J. Organ. Comput. Electron. Commer., vol. 26, no. 1-2, pp. 14-40, Mar. 2016. https://doi.org/10.1080/10919392.2015.1124007

[13] G. V. Pereira; M. A. Macadar; E. M. Luciano; M. G. Testa, "Delivering public value through open government data initiatives in a Smart City context,” Inf. Syst. Front., vol. 19, no. 2, pp. 213-229, Jul. 2016. https://doi.org/10.1007/s10796-016-9673-7

[14] G. Viscusi; M. Castelli; C. Batini, "Assessing Social Value in Open Data Initiatives: A Framework," Futur. Internet, vol. 6, no. 3, pp. 498-517, Aug. 2014. https://doi.org/10.3390/fi6030498

[15] J. Attard; F. Orlandi; S. Scerri; S. Auer, "A systematic review of open government data initiatives," Gov. Inf. Q., vol. 32, no. 4, pp. 399-418, Oct. 2015. https://doi.org/10.1016/j.giq.2015.07.006

[16] G. Bedi; G. K. Venayagamoorthy; R. Singh; R. R. Brooks; K. C. Wang, "Review of Internet of Things (IoT) in Electric Power and Energy Systems," IEEE Internet Things J., vol. 5, no. 2, pp. 847-870, Feb. 2018. https://doi.org/10.1109/JIOT.2018.2802704

[17] B. A. Potosí-Guerrero; C. A. Ramos-Paja; S. I. Serna-Garcés, "Impact of government incentives in the profitability of green energy production using fuel cells in Colombia," TecnoLógicas, vol. 19, no. 37, pp. 93106, Jul. 2016. https://doi.org/10.22430/22565337.84 
[18] S. Knudsen et al., "Democratizing open energy data for public discourse using visualization," Conf. Hum. Factors Comput. Syst. - Proc., vol. 2018, no. D406, pp. 1-4, Apr. 2018. https://doi.org/10.1145/3170427.3186539

[19] A. Francisco; J. E. Taylor, "Understanding citizen perspectives on open urban energy data through the development and testing of a community energy feedback system," Appl. Energy, vol. 256, p. 113804, Dec. 2019. https://doi.org/10.1016/j.apenergy.2019.113804

[20] C. Miller, "More Buildings Make More Generalizable Models-Benchmarking Prediction Methods on Open Electrical Meter Data," Mach. Learn. Knowl. Extr., vol. 1, no. 3, pp. 974-993, Aug. 2019. https://doi.org/10.3390/make1030056

[21] B. Anthony Jnr, "Smart city data architecture for energy prosumption in municipalities: concepts, requirements, and future directions," Int. J. Green Energy, vol. 17, no. 13, pp. 827-845, Aug. 2020. https://doi.org/10.1080/15435075.2020.1791878

[22] F. Terroso-Saenz; A. González-Vidal; A. P. Ramallo-González; A. F. Skarmeta, "An open IoT platform for the management and analysis of energy data," Futur. Gener. Comput. Syst., vol. 92, pp. 1066-1079, Mar. 2019. https://doi.org/10.1016/j.future.2017.08.046

[23] A. Salazar-Zuluaga; L. A. Aguilar-Londoño; G. D. Zapata-Madrigal; R. García-Sierra, "Implementación de Nodos Lógicos DER IEC 61850-7-420 en una placa electrónica,” TecnoLógicas, vol. 20, no. 40, pp. 13-28, Sep. 2017. https://doi.org/10.22430/22565337.701

[24] N. Andreadou; M. O. Guardiola; G. Fulli, "Telecommunication technologies for smart grid projects with focus on smart metering applications," Energies, vol. 9, no. 5, May. 2016. https://doi.org/10.3390/en9050375

[25] L. Tightiz; H. Yang, "A comprehensive review on IoT protocols' features in smart grid communication," Energies, vol. 13, no. 11, Jun. 2020. https://doi.org/10.3390/en13112762

[26] A. Karpenko et al., "Data exchange interoperability in iot ecosystem for smart parking and EV charging," Sensors, vol. 18, no. 12, Dec. 2018. https://doi.org/10.3390/s18124404

[27] O. Heddebaut; F. Di Ciommo, "City-hubs for smarter cities. The case of Lille 'EuraFlandres' interchange," Eur. Transp. Res. Rev., vol. 10, pp. 1-14, Dec. 2018. https://doi.org/10.1007/s12544-017-0283-3

[28] R. Lea; M. Blackstock, "City hub: A cloud-based IoT platform for smart cities," 2014 IEEE 6th International Conference on Cloud Computing Technology and Science, Singapore, 2015, pp. 799-804. https://doi.org/10.1109/CloudCom.2014.65

[29] M. Bajer, "Building an IoT data hub with elasticsearch, Logstash and Kibana," Proc. - 2017 5th Int. Conf. Futur. Internet Things Cloud Work, Prague, 2017, pp. 63-68. https://doi.org/10.1109/FiCloudW.2017.101

[30] A. Gyrard; C. Bonnet; K. Boudaoud, "Enrich machine-to-machine data with semantic web technologies for cross-domain applications," 2014 IEEE World Forum Internet Things, WF-IoT, Seoul, 2014, pp. 559-564. https://doi.org/10.1109/WF-IoT.2014.6803229

[31] R. Saputro; I. Pappel; H. Vainsalu; S. Lips; D. Draheim, "Prerequisites for the Adoption of the X - Road Interoperability and Data Exchange Framework: A Comparative Study," 2020 7th Int. Conf. eDemocracy eGovernment, ICEDEG, Buenos Aires, $2020, \quad$ pp. 222. https://doi.org/10.1109/ICEDEG48599.2020.9096704

[32] Nokia, "Nokia and Telia Finland fire up new innovation hub offering blistering 5G speeds to spark creativity," Dec. 05, 2019. https://www.nokia.com/about-us/news/releases/2019/12/05/nokia-and-teliafinland-fire-up-new-innovation-hub-offering-blistering-5g-speeds-to-spark-creativity/

[33] S. Li; L. Da Xu; S. Zhao, "5G Internet of Things: A survey,” J. Ind. Inf. Integr., vol. 10, pp. 1-9, Jun. 2018. https://doi.org/10.1016/J.JII.2018.01.005

[34] D. Minoli; B. Occhiogrosso, "Practical Aspects for the Integration of 5G Networks and IoT Applications in Smart Cities Environments," Wirel. Commun. Mob. Comput., vol. 2019, Aug. 2019. https://doi.org/10.1155/2019/5710834

[35] F. Al-Turjman, "5G-enabled devices and smart-spaces in social-IoT: An overview," Futur. Gener. Comput. Syst., vol. 92, pp. 732-744, Mar. 2019. https://doi.org/10.1016/j.future.2017.11.035

[36] Nordic Institute for Interoperability Solutions, "X-Road® Architecture.” https://x-road.global/architecture

[37] Nordic Institute for Interoperability Solutions, "X-Road." https://github.com/nordic-institute/X-Road

[38] A. Dagoumas, "Assessing the impact of cybersecurity attacks on power systems," Energies, vol. 12, no. 4, Feb. 2019. https://doi.org/10.3390/en12040725

[39] M. Bolaños Gonzalez; C. Collazos; F. Gutiérrez Vela, "Reference Framework for Measuring the Level of Technological Acceptance by the Elderly: A Virtual Assistants Case Study," TecnoLógicas, vol. 24, no. 50, pp. 1-16, 2021. https://doi.org/10.22430/22565337.1791 